\title{
The soxRS response of Escherichia coli can be induced in the absence of oxidative stress and oxygen by modulation of NADPH content
}

\author{
Correspondence \\ Néstor Carrillo \\ carrillo@ibr.gov.ar
}

Received 3 March 2010

Revised 16 December 2010

Accepted 21 December 2010

\author{
Adriana R. Krapp, María Victoria Humbert and Néstor Carrillo
}

Instituto de Biología Molecular y Celular de Rosario (IBR, CONICET), Facultad de Ciencias Bioquímicas y Farmacéuticas, Universidad Nacional de Rosario, Suipacha 531, S2002LRK Rosario, Argentina

The soxRS regulon protects Escherichia coli cells against superoxide and nitric oxide. Oxidation of the SoxR sensor, a [2Fe-2S]-containing transcriptional regulator, triggers the response, but the nature of the cellular signal sensed by SoxR is still a matter of debate. In vivo, the sensor is maintained in a reduced, inactive state by the activities of SoxR reductases, which employ $\mathrm{NADPH}$ as an electron donor. The hypothesis that NADPH levels affect deployment of the soxRS response was tested by transforming $E$. coli cells with genes encoding enzymes and proteins that lead to either build-up or depletion of the cellular NADPH pool. Introduction of $\mathrm{NADP}^{+}$-reducing enzymes, such as wheat non-phosphorylating glyceraldehyde-3-phosphate dehydrogenase or E. coli malic enzyme, led to NADPH accumulation, inhibition of the soxRS regulon and enhanced sensitivity to the superoxide propagator methyl viologen (MV). Conversely, expression of pea ferredoxin $(\mathrm{Fd})$, a redox shuttle that can oxidize NADPH via ferredoxin-NADP $(H)$ reductase, resulted in execution of the soxRS response in the absence of oxidative stress, and in higher tolerance to MV. Processes that caused NADPH decline, including oxidative stress and Fd activity, correlated with an increase in total $\left(\mathrm{NADP}^{+}+\mathrm{NADPH}\right)$ stocks. SoxS expression can be induced by Fd expression or by MV in anaerobiosis, under conditions in which NADPH is oxidized but no superoxide can be formed. The results indicate that activation of the soxRS regulon in E. coli cells exposed to superoxide-propagating compounds can be triggered by depletion of the NADPH stock rather than accumulation of superoxide itself. They also suggest that bacteria need to finely regulate homeostasis of the $\operatorname{NADP}(\mathrm{H})$ pool to enable proper deployment of this defensive response.

\section{INTRODUCTION}

Reactive oxygen species (ROS), such as hydrogen peroxide $\left(\mathrm{H}_{2} \mathrm{O}_{2}\right)$ and the superoxide and hydroxyl radicals, can be formed as byproducts of respiration and photosynthesis, or as a consequence of enzyme auto-oxidation and oxidase activities (Apel \& Hirt, 2004). They are able to react with a wide range of biomolecules, including proteins, lipids and nucleic acids, leading to cell stasis and death (Imlay, 2008). Aerobes have evolved a multi-tasked assortment of protective devices to prevent ROS formation, scavenge ROS once generated, and repair the damage (Imlay, 2008). Whenever ROS build-up overcomes the cellular defence barriers, the outcome is oxidative stress.

The protective responses to ROS exposure have been most thoroughly investigated in Escherichia coli. The bulk of the

Abbreviations: Fd, ferredoxin; FPR, ferredoxin-NADP(H) reductase; G6PDH, glucose-6-phosphate dehydrogenase; GAPN, non-phosphorylating glyceraldehyde-3-phosphate dehydrogenase; MV, methyl viologen; ROS, reactive oxygen species. defensive resources in this species are grouped into two commonly regulated suites of genes belonging to the soxRS and $\operatorname{xyy} R$ regulons (Pomposiello et al., 2001; Blanchard et al., 2007; Imlay, 2008). The E. coli transcriptional activator OxyR induces expression of the $o x y R$ regulon in response to peroxide treatment, while the soxRS system confers tolerance to superoxide and nitric oxide. The sensor of this regulon is the SoxR protein, a dimeric transcription factor that contains [2Fe-2S] centres (Watanabe et al., 2008). When E. coli cells are exposed to superoxidepropagating compounds such as the redox-cycling herbicide methyl viologen (MV), the iron-sulphur cluster of SoxR undergoes univalent oxidation to yield the oxidized, active protein. The only known target of activated SoxR is the soxS gene (Pomposiello et al., 2001). Increased SoxS levels, in turn, induce expression of more than 100 genes (Blanchard et al., 2007). Different components of the soxRS regulon combat the toxic effects of oxidants at various levels, including ROS scavenging, replacement of sensitive targets by resistant counterparts and damage repair (Imlay, 2008). 
Despite the wealth of knowledge on the components of the soxRS response and their mechanism of action, it is still unclear how the oxidative stress condition is sensed by the SoxR protein. Indeed, it is likely that superoxide is not the only oxidant involved in this process, and maybe not even the most important. Liochev \& Fridovich (1992) were first to propose that the inducing signal could be a decrease in NADPH levels caused by NADPH oxidation during the generation of superoxide, although the contention has not been rigorously tested. NADPH could keep SoxR reduced and inactive in vivo by the action of at least two different SoxR reductases, both using NADPH as electron donor (Kobayashi \& Tagawa, 1999; Koo et al., 2003).

In metabolic terms, $\mathrm{NAD}^{+}$serves primarily for energy production and NADPH as a hydride donor for biosynthetic reactions. In addition, NADPH is the reductant or essential cofactor for several enzymes involved in protective and/or antioxidant activities, including glutathione reductase (GR), thioredoxin reductase, NADPH-dependent alkylhydroperoxidase and nitroreductase (Paterson et al., 2002; Imlay, 2008). Notably, several components of the soxRS and oxyR systems, such as glucose-6-phosphate dehydrogenase $(\mathrm{G} 6 \mathrm{PDH})$, ferredoxin-NADP $(\mathrm{H})$ reductase (FPR), flavodoxin, GR and hydroperoxidase I are NADPHlinked enzymes or proteins. NADPH formation appears to be stimulated when bacteria are exposed to either superoxide radicals (Pomposiello et al., 2001) or $\mathrm{H}_{2} \mathrm{O}_{2}$ (Brumaghim et al., 2003), suggesting that its accumulation is essential to cope with oxidative stress. On the other hand, high NADPH levels might have pro-oxidant effects by reducing transition metals to their more toxic states (Brumaghim et al., 2003).

The aim of this study was to investigate how directed alterations in NADPH levels affect both deployment of the soxRS response and tolerance to oxidative stress in E. coli. It was found that transformation of $E$. coli with genes encoding enzymes that reduce $\mathrm{NADP}^{+}$led to build-up of NADPH content, downregulation of the soxRS response and higher sensitivity to $\mathrm{MV}$ and $\mathrm{H}_{2} \mathrm{O}_{2}$. Conversely, expression of an NADPH consumer, chloroplast ferredoxin (Fd), resulted in the opposite behaviour. Moreover, NADPH oxidation by Fd or by the NADPH-diaphorase acceptor MV led to significant SoxS accumulation in anaerobiosis, when no superoxide could be formed. Total $\left(\mathrm{NADP}^{+}+\mathrm{NADPH}\right)$ levels significantly increased in response to NADPH declines, and vice versa. These observations indicate that $\mathrm{NADPH}$ homeostasis plays a critical role in proper execution of the soxRS response.

\section{METHODS}

Plasmid construction. The gapn cDNA encoding wheat nonphosphorylating glyceraldehyde-3-phosphate dehydrogenase (GAPN), present in plasmid pRSETB-GAPN, was PCR-amplified using primers ttgaattcaatggcggggacgggg (forward) and aagctttcagcccatggtgtaggac (reverse) (restriction sites for EcoRI and Hind III in bold, translation start and stop sites in bold and underlined). The product was cloned in
pGEM-T-easy (Table 1), digested with EcoRI and HindIII, and ligated to compatible sites of pUC18. The resulting plasmid, pUCGAPN, was transformed into E. coli BL21(DE3) codon plus (CP) (Table 1). The recombinant protein was expressed under the control of the lac promoter fused in-frame to the first five amino acids of the lac $Z$ gene product. The GAPN activity of soluble cell extracts was determined spectrophotometrically according to Bustos \& Iglesias (2002).

E. coli malic enzyme was expressed from plasmid pETMAE under control of the strong T7 promoter that drives expression of this gene, using the inducer IPTG. This vector was prepared by cloning the coding region of the E. coli maeB gene into BamHI/HindIII sites of pET28b as described below. The maeB gene present in plasmid pGEMT-MaeB (Bologna et al., 2007) was amplified by PCR using two primers with BamHI/HindIII restriction sites. The forward and reverse oligonucleotides were designed to hybridize to positions 1-15 and 2262-2280 of the maeB gene, respectively, counting from the translation initiation site. The PCR product was digested and ligated into compatible sites in pET28b. Expression of malic enzyme was verified by activity measurements and Western blotting.

Plasmid pSUFd was prepared by cloning the mature region of pea Fd1 into the BamHI/HindIII sites of pSU18. This sequence of $350 \mathrm{bp}$ was amplified by PCR from a cDNA encoding the protein (Catalano Dupuy et al., 2004), using primers gatcttgcggatcctatggcttcttac (forward) and ccacaagcttgatatcatatcatagcatagcagt (reverse) with specific restriction sites in bold. Fd was expressed with 11 additional amino acids as a result of the $\mathrm{N}$-terminal fusion to $\beta$-galactosidase, and under control of the lac promoter. Details of pETFd construction are given elsewhere (Catalano Dupuy et al., 2004). From this plasmid, mature pea $\mathrm{Fd}$ was expressed as a soluble protein in high yield under control of the T7 promoter and a RBS provided by the pET28a vector.

Antibiotics (Table 1) were used at the following concentrations: ampicillin, $100 \mu \mathrm{g} \mathrm{ml}^{-1}$; chloramphenicol, $25 \mu \mathrm{g} \mathrm{ml}^{-1}$; kanamycin, $40 \mu \mathrm{g} \mathrm{ml}^{-1}$.

Determination of $\boldsymbol{\beta}$-galactosidase activity. Fd expression in E. coli BL21(DE3) CP transformed with pETFd was driven by T7 RNA polymerase in LB broth containing $60 \mu \mathrm{M} \mathrm{FeSO}_{4}$ and $0.1 \mathrm{mM}$ EDTA. These cells also contained plasmid pTN1530, bearing a soxS $S^{\prime}:$ lac $Z^{\prime}$ operon fusion (Table 1). Bacterial cultures were incubated for $90 \mathrm{~min}$ before IPTG addition, and samples were collected at various times in pre-chilled tubes to measure $\beta$-galactosidase activity (Miller, 1992).

Determination of SoxS and FPR expression. Overnight cultures of $E$. coli cells transformed with pUCGAPN, pETMAE, pETFd and the corresponding empty plasmids were diluted $(1: 100)$ in $50 \mathrm{ml} \mathrm{LB}$ medium supplemented with the corresponding antibiotics and $0.5 \mathrm{mM}$ IPTG. Bacterial suspensions were incubated at $30{ }^{\circ} \mathrm{C}$ (pUCGAPN) or $37^{\circ} \mathrm{C}$ (pETMAE and pETFd) to $\mathrm{OD}_{600} 0.6-0.8$. Suspensions were split into two equal portions and MV was then added to one of these at a final concentration of $0.5 \mathrm{mM}$. At the times indicated in the legends to Figs 2, 3 and 4, cells were collected by centrifugation $(10 \mathrm{~min}$ at $7000 \mathrm{~g})$, resuspended in $50 \mathrm{mM}$ Tris/ $\mathrm{HCl}$, pH 8, 1 mM EDTA, 0.1 mM PMSF, disrupted by sonic oscillation (5 times for $6 \mathrm{~s}$ each, $20 \%$ amplitude), and centrifuged (15 min at $18000 \mathrm{~g}$ ). Soluble fractions were resolved by SDS-PAGE and transferred to nylon membranes, where SoxS and FPR were detected with specific antisera using secondary antibodies conjugated to alkaline phosphatase.

For experiments performed under anaerobic conditions, overnight aerobic cultures were diluted $(1: 50)$ in $12 \mathrm{ml}$ degassed LB broth and incubated at $37{ }^{\circ} \mathrm{C}$ for $18 \mathrm{~h}$ in a BBL Gas-Pak jar with MV. An anaerobic atmosphere was obtained with the bioMériux envelope system. Cells were collected on ice and broken by sonic oscillation. Cleared lysates were analysed by SDS-PAGE and immunoblotting. 
Table 1. E. coli strains and plasmids used in this study

\begin{tabular}{|c|c|c|}
\hline Strain or plasmid & Genotype or relevant characteristics* & Source or reference \\
\hline \multicolumn{3}{|l|}{ Strains } \\
\hline BL21(DE3) CP & $\begin{array}{l}\mathrm{F} 2 \operatorname{omp} T \text { hsdSB }\left(\mathrm{r}_{\mathrm{B}}^{-} \mathrm{m}_{\mathrm{B}}^{-}\right) d c m \text { gal BL21(DE3), } \mathrm{Cam}^{\mathrm{r}} \text {, tRNAs } \arg U \\
\text { (AGA, AGG), ileY (AUA), leuW (CUA) }\end{array}$ & Stratagene \\
\hline BL21(DE3) & $\mathrm{F} 2$ ompT hsdSB $\left(\mathrm{r}_{\mathrm{B}}^{-} \mathrm{m}_{\mathrm{B}}^{-}\right) d c m$ gal BL21(DE3) & Stratagene \\
\hline B247 & 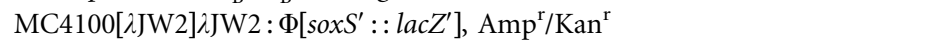 & Wu \& Weiss (1992) \\
\hline \multicolumn{3}{|l|}{ Plasmids } \\
\hline pGEM T-easy & Vector for cloning PCR products & Promega \\
\hline pUC18 & $A m p^{r}$ & Takara Bio \\
\hline pUCGAPN & pUC18 with the Tagapn gene under control of the lac promoter & This study \\
\hline pSU18 & Derivative of pACYC containing the lacZ gene of pUC18, $\mathrm{Cam}^{\mathrm{r}}$ & Martínez et al. (1988) \\
\hline pSUFd & pSU18 with the coding region of mature pea Fd1 & This study \\
\hline pETFd & pET28a carrying the coding region of mature pea Fd1 gene, $\operatorname{Kan}^{r}$ & Catalano Dupuy et al. (2004) \\
\hline pETSoxS & pET28a with the soxS gene, used to obtain recombinant SoxS & This study \\
\hline
\end{tabular}

${ }^{\star} A m p^{r}$, Ampicillin resistance; $\mathrm{Cam}^{\mathrm{r}}$, chloramphenicol resistance; $\mathrm{Kan}^{\mathrm{r}}$, kanamycin resistance.

Immunoreactive bands were integrated after scanning using the Gel-Pro Analyser 4.0 software pack (Media Cybernetics).

Susceptibility assays. In the disc diffusion assay, $100 \mu \mathrm{l}$ bacterial suspension containing $\sim 10^{8}$ cells was mixed with $3 \mathrm{ml} 0.7 \%(\mathrm{w} / \mathrm{v})$ warm molten agar and poured onto LB agar plates. After hardening, $\mathrm{MV}$ and $\mathrm{H}_{2} \mathrm{O}_{2}$ solutions were added in $5 \mu \mathrm{l}$ aliquots to paper discs ( $5 \mathrm{~mm}$ diameter) placed on the agar surface. Zones of growth inhibition were measured after incubation for $24 \mathrm{~h}$ at $30{ }^{\circ} \mathrm{C}$ (pUCGAPN) or $37^{\circ} \mathrm{C}$ (pETFd).

Determination of NADP ${ }^{+}$and NADPH concentrations. Cultures of E. coli BL21 DE3 CP transformed with pUC18, pUCGAPN, pET28a or pETFd were grown aerobically in LB broth $(300 \mathrm{ml}$ in a $1000 \mathrm{ml}$ flask) with the appropriate antibiotics and IPTG. When the cultures reached $\mathrm{OD}_{600} 0.5$, quadruplicate samples of $15 \mathrm{ml}$ were taken $(t=0)$ and $0.5 \mathrm{mM} \mathrm{MV}$ was added. Samples were withdrawn at 30, 60 and $120 \mathrm{~min}$ and frozen at $-70{ }^{\circ} \mathrm{C}$. Pyridine nucleotides were estimated by the method of Slater \& Sawyer (1962), with the following modifications. Cellular pellets corresponding to $15 \mathrm{ml}$ of culture were resuspended in $200 \mu \mathrm{l} 0.2 \mathrm{M} \mathrm{HCl}$ or in $400 \mu \mathrm{l} 0.2 \mathrm{M}$ $\mathrm{NaOH}$, and centrifuged at $16000 \mathrm{~g}$ for $10 \mathrm{~min}$. Supernatants were heated at $95{ }^{\circ} \mathrm{C}$ for $90 \mathrm{~s}$ and immediately neutralized with $1 \mathrm{M}$ Tris/ $\mathrm{HCl} \mathrm{pH} 8$ to $\mathrm{pH} 5-6\left(\mathrm{NADP}^{+}\right.$determinations), or with $0.2 \mathrm{M} \mathrm{HCl}$ to $\mathrm{pH}$ 7-8 (NADPH measurements). Known amounts of $\mathrm{NADP}^{+}$ and NADPH were added to the lysates prior to the heating step to estimate recovery. The reaction was carried out in $1 \mathrm{ml} 25 \mathrm{mM}$ Tris/HCl pH 8, $1 \mathrm{mM}$ glucose 6-phosphate, $100 \mu \mathrm{M}$ 2,6-dichlorophenol indophenol, $0.5 \mathrm{mM}$ phenazine methosulphate, 2 units G6PDH ml ${ }^{-1}$ and $25-50 \mu \mathrm{l}$ sample, following the change of absorbance at $600 \mathrm{~nm}$. Concentrations were calculated from a $\mathrm{NADP}^{+} / \mathrm{NADPH}$ standard curve $(0-500 \mathrm{pmol})$.

Protein concentrations were estimated in cleared lysates by a dye-binding method (Sedmak \& Grossberg, 1977), using BSA as standard.

Statistical analyses. Statistical differences between treatments and strains were analysed by a two-sided $t$-test.

\section{RESULTS}

\section{NADPH accumulation causes downregulation of the soxRS response of $E$. coli}

We have previously shown that E. coli cells overexpressing G6PDH from a multicopy plasmid accumulated higher NADPH levels and displayed a protracted soxRS response (Giró et al., 2006). However, G6PDH (encoded by the $z w f$ gene) is itself induced during the process (Blanchard et al., 2007), complicating interpretation of the results. To compare the effect of NADPH build-up in a manner that is independent of endogenous regulatory networks, we cloned a wheat gene encoding GAPN (Bustos \& Iglesias, 2002) in pUC18 to yield pUCGAPN, and used the resulting plasmid to transform bacteria from the E. coli BL21(DE3) CP (Table 1). This enzyme was chosen because no endogenous GAPN activity has been reported in E. coli (Iddar et al., 2005).

After IPTG induction, the foreign enzyme accumulated in the cytosol of pUCGAPN-transformed cells. Specific GAPN activities increased more than 250 -fold in these bacteria, relative to cells harbouring pUC18 $[161.0 \pm 14.0$ vs $0.6 \pm$ $0.2 \mu \mathrm{mol}$ (mg protein $)^{-1} \mathrm{~min}^{-1}$ ]. Expression of GAPN led to a significant increase (from 0.72 to 2.45 ) in the $\mathrm{NADPH}: \mathrm{NADP}^{+}$ratio during the exponential growth phase, accompanied by a $20-25 \%$ decrease in total $\left(\mathrm{NADP}^{+}+\mathrm{NADPH}\right)$ contents (Table 2). Exposure of cells transformed with either pUCGAPN or pUC18 to $0.5 \mathrm{mM}$ MV in liquid LB broth had little or no effect on the $\mathrm{NADPH} / \mathrm{NADP}^{+}$ratio, which declined less than $20 \%$ in both strains. Instead, the treatment led to a timedependent increase of the total $\left(\mathrm{NADP}^{+}+\mathrm{NADPH}\right)$ pool 
Table 2. Effect of MV exposure on $\operatorname{NADP}(H)$ levels in $E$. coli cells expressing GAPN or Fd

E. coli BL21(DE3) CP cells harbouring the plasmids indicated were inoculated in LB broth supplemented with the appropriate antibiotics, $0.5 \mathrm{mM}$ IPTG and, in the case of pET28a- and pETFd-transformed bacteria, $60 \mu \mathrm{M} \mathrm{FeSO}$ and $0.1 \mathrm{mM}$ EDTA. When present, MV concentration was $0.5 \mathrm{mM}$. Samples were withdrawn after $2 \mathrm{~h}$ incubation at $30{ }^{\circ} \mathrm{C}$ (pUCGAPN) or $37{ }^{\circ} \mathrm{C}$ (pETFd) for determination of $\mathrm{NADP}^{+}, \mathrm{NADPH}$ and protein as described in Methods. Each value represents the mean \pm SEM of three determinations.

\begin{tabular}{|c|c|c|}
\hline $\begin{array}{l}\text { Plasmid and } \\
\text { treatment }\end{array}$ & $\begin{array}{c}\text { NADPH }: \mathrm{NADP}^{+} \\
\text {ratio }\end{array}$ & 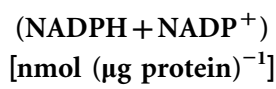 \\
\hline pUC18 & $0.72 \pm 0.18$ & $0.94 \pm 0.12$ \\
\hline pUC18+MV & $0.62 \pm 0.14$ & $2.92 \pm 0.2$ \\
\hline pUCGAPN & $2.45 \pm 0.52$ & $0.73 \pm 0.15$ \\
\hline pUCGAPN + MV & $1.96 \pm 0.40$ & 1.68. \pm 0.2 \\
\hline pET28a & $0.82 \pm 0.20$ & $1.02 \pm 0.13$ \\
\hline pET28 + MV & $0.65 \pm 0.16$ & $3.01 \pm 0.18$ \\
\hline pETFd & $0.35 \pm 0.09$ & $1.7 \pm 0.21$ \\
\hline $\mathrm{pETFd}+\mathrm{MV}$ & $0.30 \pm 0.06$ & $4.58 \pm 0.2$ \\
\hline
\end{tabular}

during the $2 \mathrm{~h}$ time-frame of the experiment (Fig. 1). The $\left(\mathrm{NADP}^{+}+\mathrm{NADPH}\right)$ build-up followed similar timecourses in the two strains, with GAPN-expressing bacteria displaying lower levels at all times assayed. Cells incubated during the same period in the absence of MV displayed only marginal alterations in total $\left(\mathrm{NADP}^{+}+\mathrm{NADPH}\right)$ amounts (Fig. 1), indicating that the increase was caused by the herbicide.

Induction of the soxRS response in these MV-treated cells was evaluated by immunoblot analysis of SoxS. In the absence of oxidative stress, SoxS could not be detected, irrespective of GAPN expression (Fig. 2a, lanes 1 and 6). After MV exposure, an immunoreactive band coincident with the molecular mass of SoxS $(\sim 12 \mathrm{kDa})$ was visualized in extracts from both strains, although SoxS was poorly induced in GAPN-expressing bacteria relative to cells transformed with the empty vector (Fig. 2a), as estimated in a number of assays. Evaluation of the SoxS target gene $f p r$, encoding FPR, gave similar results (Fig. 2b), supporting the notion that the soxRS regulon was induced to a significantly lower extent in GAPN-expressing high-NADPH cells.

To confirm that the effects observed were caused by alterations of NADPH levels and not by GAPN expression itself or some other consequence of GAPN activity, similar experiments were carried out with BL21(DE3) cells transformed with plasmid pETMAE overexpressing the E. coli $\mathrm{NADP}^{+}$-specific malic enzyme, which reduces $\mathrm{NADP}^{+}$ during the oxidative decarboxylation of malate (Bologna et al., 2007). Exposure of pETMAE-transformed bacteria to MV led to induction of SoxS (Fig. 2c, lanes 5 and 6), but to a lower level than siblings containing the supporting plasmid alone (Fig. 2c, lanes 2 and 3), and even lower than that for GAPN-expressing bacteria (Fig. 2a).

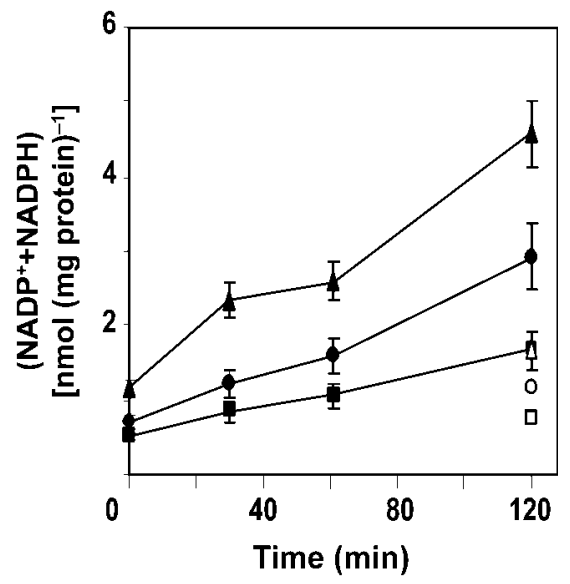

Fig. 1. Accumulation of $\left(\mathrm{NADP}^{+}+\mathrm{NADPH}\right)$ in $E$. coli cells exposed to MV. Bacteria transformed with pUC18 or pET28a

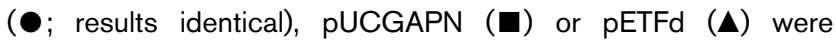
incubated with $0.5 \mathrm{mM} \mathrm{MV}$ in LB broth at $30{ }^{\circ} \mathrm{C}$ (pUCGAPN) or $37{ }^{\circ} \mathrm{C}$ ( $\left.p E T F d\right)$ with vigorous shaking. At the times indicated, aliquots were withdrawn to determine $\mathrm{NADP}^{+}, \mathrm{NADPH}$ and protein contents as described in Methods. The corresponding open symbols indicate samples of each strain that were incubated in the absence of MV. Each data point represents the mean \pm SEM of three determinations.

\section{Expression of a plant ferredoxin induces the soxRS response of $E$. coli in the absence of oxidative stress}

Since NADPH build-up resulted in inhibition of the soxRS response under oxidative stress, we evaluated whether NADPH consumption by an introduced electron acceptor could boost the response when no oxidants were present. $\mathrm{Fd}$ is an iron-sulphur protein which can oxidize NADPH to $\mathrm{NADP}^{+}$via FPR (Carrillo \& Ceccarelli, 2003). E. coli Fd, unlike the isofunctional electron shuttle flavodoxin, does not belong to the soxRS regulon (Blanchard et al., 2007). We cloned a pea gene encoding chloroplast Fd1 in the multicopy plasmid pET28a under control of the T7 RNA polymerase promoter (pETFd, Table 1), and used it to transform E. coli BL21(DE3) CP that contained a second plasmid (pTN1530) harbouring a soxS'::lacZ' fusion. Plant Fd can act as a substrate of E. coli FPR (Giró et al., 2006).

The foreign Fd was produced at high yields upon induction of the transformed bacteria with $0.5 \mathrm{mM}$ IPTG, as revealed by SDS-PAGE and immunoblot analysis with specific antisera (Fig. 3a). At these expression levels, iron might become limiting, so the medium was supplemented with $60 \mu \mathrm{M} \mathrm{FeSO}$ and $0.1 \mathrm{mM} \mathrm{EDTA}$ to ensure that the expressed protein was functional as an electron acceptor. Accumulation of an active $\mathrm{Fd}$ led to a drop in the $\mathrm{NADPH}: \mathrm{NADP}^{+}$ratio relative to cells transformed with pET28a (0.35 vs 0.82$)$, paralleled by a $70 \%$ increase in total $\left(\mathrm{NADP}^{+}+\mathrm{NADPH}\right)$ content (Table 2). On exposure 
(a)

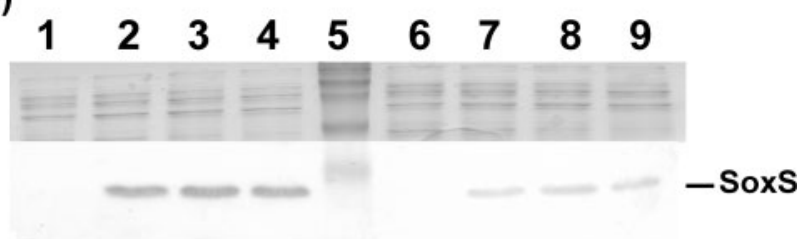

(b)

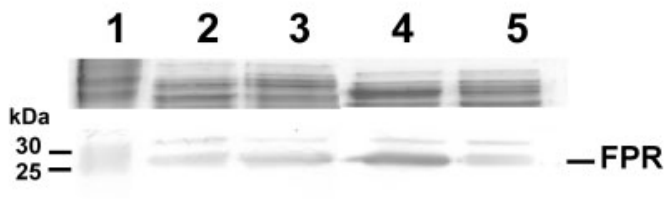

(c)

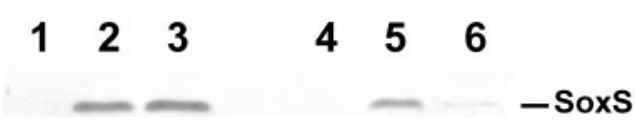

Fig. 2. Expression of enzymes that produce NADPH causes downregulation of the soxRS response of E. coli. (a) Cells transformed with pUC18 (lanes 1-4) or pUCGAPN (lanes 6-9) were challenged with $0.5 \mathrm{mM} \mathrm{MV}$ as described in Methods. Aliquots were taken after 0 (lanes 1 and 6), 30 (lanes 2 and 7), 60 (lanes 3 and 8) and 120 min (lanes 4 and 9) of MV treatment, cells were ruptured by sonic oscillation, and cleared lysates corresponding to $7 \mu \mathrm{g}$ total soluble protein were analysed by SDSPAGE and immunoblotting using anti-SoxS antiserum. Lane 5, molecular mass standards. (b) Immunoblots of extracts corresponding to bacteria transformed with pUC18 (lanes 2 and 4) or pUCGAPN (lanes 3 and 5) incubated in the absence (lanes 2 and 3 ) or in the presence (lanes 4 and 5) of MV for $2 \mathrm{~h}$. Extracts corresponding to $7 \mu \mathrm{g}$ total soluble protein were analysed by SDS-PAGE and immunoblotting using anti-FPR antiserum. Lane 1, molecular mass markers. (c) Cells transformed with pET28b (lanes 1-3) or pETMAE (lanes 4-6) were challenged with $0.5 \mathrm{mM} \mathrm{MV}$ for 0 (lanes 1 and 4), 30 (lanes 2 and 5) and 60 min (lanes 3 and 6) as described in Methods. Samples were processed and analysed with anti-SoxS antiserum as described for (a). The upper parts of panels (a) and (b) show Coomassie brilliant blue-stained portions of the gels as loading controls.

of the cells to $0.5 \mathrm{mM} \mathrm{MV},\left(\mathrm{NADP}^{+}+\mathrm{NADPH}\right)$ levels increased in a time-dependent manner in both strains, with Fd-expressing cells displaying higher values at all times assayed (Fig. 1).

The extent of induction of the soxRS response was initially evaluated by measuring transcription from the sox $S^{\prime}$ promoter via $\beta$-galactosidase activity. Two hours after addition of IPTG in the absence of MV, $\beta$-galactosidase activity had increased approximately eightfold in Fdexpressing cells relative to bacteria containing pET28a alone (4720 vs 585 Miller units), suggesting transcriptional stimulation of the regulon in the absence of oxidative stress.

Activation of the soxRS response in Fd-expressing bacteria was confirmed by direct detection of SoxS in immunoblots (Fig. 3b, lane 4). When cells were exposed to MV, SoxS accumulation was higher in Fd-expressing bacteria relative to siblings transformed with the supporting vector (Fig. $3 c$ ). Addition of iron alone had no effect on the levels of SoxS (Fig. 3b, lane 2), indicating that the effect of Fd was due to its electron-accepting activity and not to the establishment of oxidative stress imposed by the transition metal. As anticipated, the SoxS target gene encoding FPR displayed a similar behaviour (Fig. 3d).

\section{Induction of the soxRS regulon in anaerobiosis}

Although the Fd results reported in the previous section indicate that soxRS induction can be accomplished by manipulation of NADPH levels in the absence of oxidants (Fig. 3b, d), the possibility of superoxide generation associated with aerobic metabolism cannot be ruled out in that experimental set-up. We therefore investigated whether the soxRS regulon can be induced by Fd expression in anaerobiosis, when superoxide formation is precluded. Fig. 4(a) shows that this was indeed the case. MV is another suitable candidate for depleting the NADPH pool since it is the electron acceptor of four different NADPH-dependent diaphorase activities (Gaudu \& Fontecave, 1994; Liochev et al., 1994). The herbicide is reduced by E. coli cells in anaerobiosis but cannot engage in redox cycling with oxygen, significantly decreasing its toxicity (Liochev et al., 1994). Addition of MV to anaerobic suspensions of E. coli cells led to rapid reduction of the dipyridyl compound to its radical form, which could be visualized by appearance of a blue colour in the medium. Under these conditions, SoxS displayed maximal accumulation at $0.5 \mathrm{mM} \mathrm{MV} \mathrm{(Fig.} \mathrm{4b,}$ lanes 2 and 3). Beyond that concentration, SoxS levels declined (Fig. 4b, lane 4), presumably reflecting increased impairment of the bacterial metabolism. Collectively, the results indicate that the soxRS regulon can be activated in anaerobiosis provided that NADPH levels are decreased by suitable electron acceptors such as Fd or MV, although the extent of induction was significantly lower than that attained under aerobiosis (Fig. 4b). These results concur with previous observations that showed anaerobic activation of the soxRS regulon by nitric oxide (Nunoshiba et al., 1993), and by diamide, a thiol oxidant expected to deplete the NADPH pool (Privalle et al., 1993). In Pseudomonas aeruginosa, phenazines can also activate SoxR anaerobically (Dietrich et al., 2006).

\section{NADPH modulates sensitivity of $E$. coli cells to oxidants}

Since NADPH accumulation in the GAPN-expressing cells resulted in a weakened induction of the soxRS response, the tolerance of these bacteria to oxidants was analysed by the disc diffusion method. E. coli cells containing pUCGAPN were more sensitive to MV than siblings transformed with pUC18 (Fig. 5a). Tolerance to MV was also assayed in E. coli B247 cells expressing Fd from the low-copy-number plasmid pSUFd (Table 1). This strain displayed an intrinsically higher sensitivity to MV toxicity as compared with 
(a)

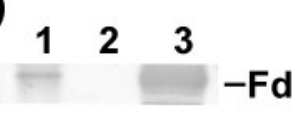

(c)
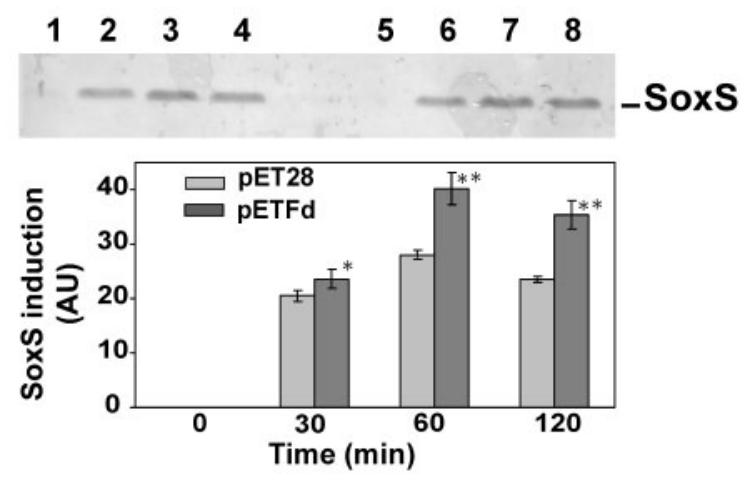

(d)

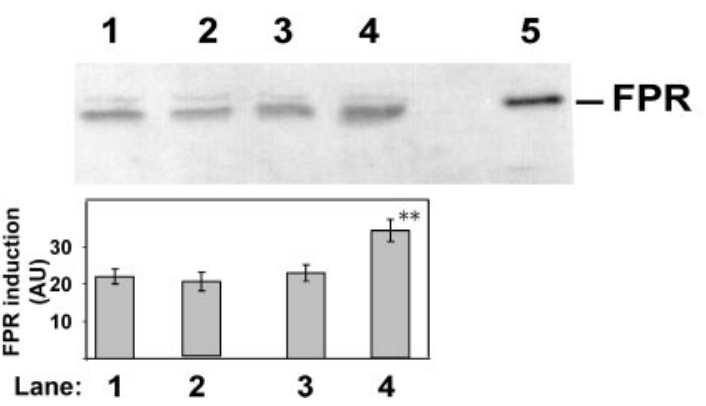

Fig. 3. NADPH consumption induces the soxRS response of $E$. coli cells in the absence of oxidative stress. (a) Fd accumulation in E. coli BL21(DE3) CP cells transformed with recombinant plasmid pETFd (Table 1). Bacteria were grown for $2 \mathrm{~h}$ after addition of $0.5 \mathrm{mM} \mathrm{IPTG}$ at $37{ }^{\circ} \mathrm{C}$ in LB broth. Cleared lysates were prepared as described in Methods and analysed by SDS-PAGE and immunoblotting using antiserum raised against pea Fd. Lane 1, purified pea $\mathrm{Fd}(25 \mathrm{ng}$ ); lanes 2 and 3, extracts corresponding to $20 \mu \mathrm{g}$ total soluble protein from bacteria transformed with $\mathrm{pET} 28 \mathrm{a}$ (lane 2) or pETFd (lane 3). (b) Cells were incubated for $2 \mathrm{~h}$ in the presence or in the absence of $\mathrm{FeSO}_{4}$ and IPTG as described in Methods. Lysates corresponding to $12 \mu \mathrm{g}$ total soluble protein were analysed by SDS-PAGE and immunoblotting using anti-SoxS antiserum. Immunoblots are shown of extracts corresponding to $E$. coli cells challenged with $0.5 \mathrm{mM} \mathrm{MV}$ as SoxS-positive control (lane 1); and of bacteria transformed with pET28a supplemented with Fe (lane 2); pETFd plus Fe (lane 3), or pETFd plus Fe and IPTG (lane 4). (c) Cells transformed with pET28a (lanes 1-4) or pETFd (lanes 5-8) were exposed to $0.5 \mathrm{mM} \mathrm{MV}$ for 0 (lanes 1 and 5), 30 (lanes 2 and 6), 60 (lanes 3 and 7) or 120 min (lanes 4 and 8 ) in the presence of $0.5 \mathrm{mM} \mathrm{IPTG}$. Cleared lysates corresponding to $7 \mu \mathrm{g}$ total soluble protein were loaded onto each lane. Immunoblot analysis with anti-SoxS antiserum was carried out as described above. The graph below the gel shows the amounts of SoxS in arbitrary units (AU; means \pm SEM of three independent determinations), calculated by scanning the immunoblots. Asterisks above each bar represent the statistical significance of the differences among strains: ${ }^{*}, P \leqslant 0.05 ;{ }^{\star *}, P \leqslant 0.001$. (d) FPR immunoblots of extracts corresponding to bacteria transformed with pET28a (lane 1); supplemented with Fe (lane 2); transformed with pETFd supplemented with Fe (lane 3), or with Fe and IPTG (lane 4). Lane 5, purified FPR (25 ng). The graph below the gel shows the amounts of FPR (mean \pm SEM of two independent determinations), as indicated in (c). ${ }^{* \star}, P \leqslant 0.001$.

BL21(DE3) CP (Fig. 5a, b), but tolerance was significantly increased in cells accumulating an active Fd (Fig. 5b).

GAPN-expressing bacteria also displayed enhanced sensitivity to $\mathrm{H}_{2} \mathrm{O}_{2}$ (Fig. 5c). Manchado et al. (2000) have reported that $\mathrm{H}_{2} \mathrm{O}_{2}$ activates the soxRS response at millimolar concentrations like those used in our assay, presumably through depletion of NADPH stocks. Interestingly, $\mathrm{H}_{2} \mathrm{O}_{2}$ toxicity was diminished in the presence of deferoxamine, an iron chelating agent (Fig. 5c), suggesting that increased sensitivity of GAPNexpressing cells results from both protracted deployment of the soxRS response and the pro-oxidant role of NADPH in providing reduced iron for Fenton-type reactions.

\section{DISCUSSION}

The results presented herein support an earlier proposal by Liochev \& Fridovich (1992), who suggested that the soxRS regulon of E. coli is able to sense the NADPH status and respond accordingly. Expression of an NADPH-producing

(a)

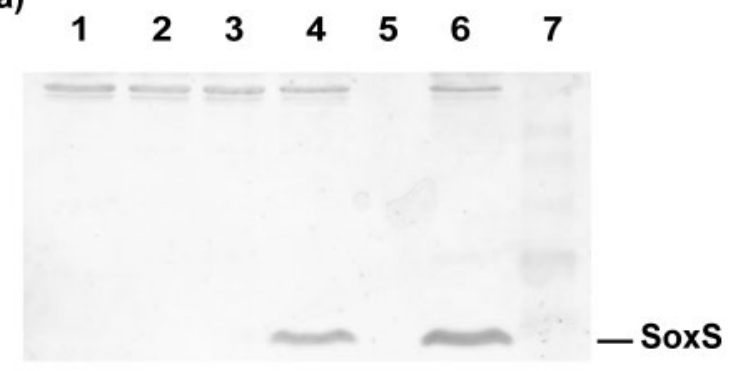

(b)

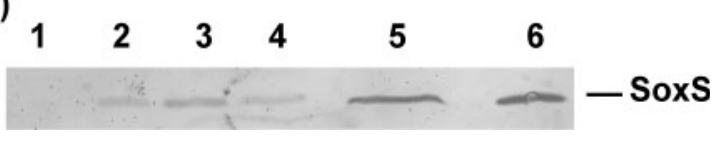

Fig. 4. NADPH depletion induces the soxRS response of $E$. coli BL21(DE3) CP in anaerobiosis. (a) Cells transformed with pET28a (lane 1), or with pETFd (lane 2) supplemented with Fe (lane 3) or Fe and IPTG (lane 4) were grown for $18 \mathrm{~h}$ in a BBL Gas-Pak jar. Bacteria were ruptured and extracts corresponding to $50 \mu \mathrm{g}$ soluble protein were analysed by immunoblotting with anti-SoxS antiserum as described in Methods. Lane 6, SoxS immunoblots of extracts corresponding to cells challenged aerobically with $0.5 \mathrm{mM}$ MV as SoxS-positive control. Lane 7, molecular mass standards. (b) Non-transformed cells were exposed for $24 \mathrm{~h}$ to the indicated concentrations of MV under the anaerobic conditions described above. Cleared extracts corresponding to $20 \mu \mathrm{g}$ soluble protein were analysed by SDS-PAGE and immunoblotting with SoxS antiserum. Lanes 1-4, cells were incubated with $0,0.2,0.5$ and $1 \mathrm{mM} \mathrm{MV}$, respectively; lane 5 , exposed to $0.5 \mathrm{mM} \mathrm{MV}$ in aerobiosis; lane 6, purified SoxS (25 ng) used as control. 
(a)

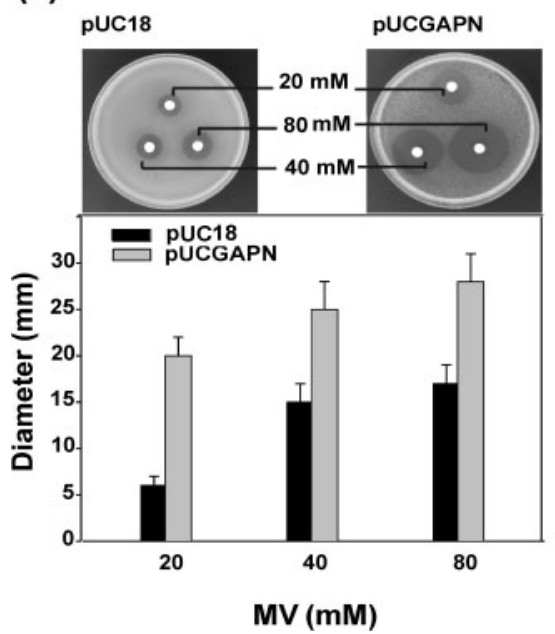

(b)

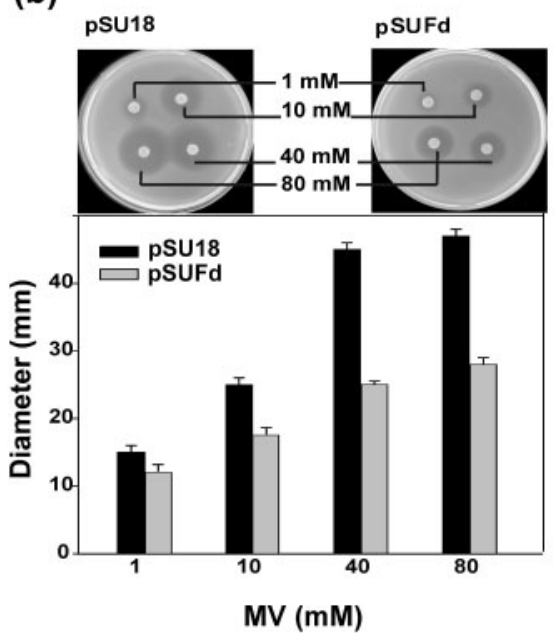

(c)

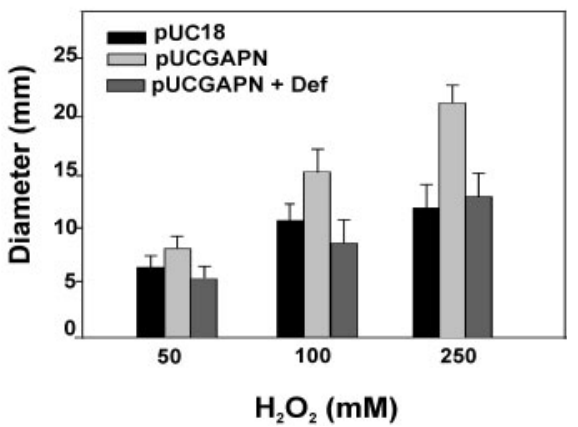

Fig. 5. Susceptibility of $E$. coli cells to $M V$ or $\mathrm{H}_{2} \mathrm{O}_{2}$ toxicity depends on expression of NADPH producers or consumers. (a) BL21(DE3) CP bacteria transformed with pUC18 or pUCGAPN were grown to exponential phase and then $0.1 \mathrm{ml}$ of the suspension was added to soft agar and poured over LB agar plates. Paper discs were charged with $5 \mu$ of the indicated concentrations of MV. (b) Expression of Fd in E. coli B247 cells transformed with pSUFd results in increased tolerance to MV in disc diffusion assays. Experimental conditions were as described for (a). (c) BL21(DE3) CP bacteria transformed with pUC18 or pUCGAPN were grown and exposed to $\mathrm{H}_{2} \mathrm{O}_{2}$ as indicated in (a). Protection by an iron-chelating agent was demonstrated by using plates supplemented with $10 \mathrm{mM}$ deferoxamine mesylate (Def). Each bar represents the mean \pm SEM of three experiments.

enzyme, GAPN, led to increased NADPH: $\mathrm{NADP}^{+}$ratios (Table 2), partially inhibited the induction of SoxRdependent components (Fig. 2), and resulted in enhanced sensitivity to redox-cycling oxidants (Fig. 5). Conversely, incorporation of an NADPH consumer such as the electron acceptor $\mathrm{Fd}$ resulted in lower $\mathrm{NADPH}: \mathrm{NADP}^{+}$ratios (Table 2), and enhanced induction of the soxRS regulon in the absence of oxidative stress or even of oxygen (Figs 3 and 4). These results agree with previous observations indicating that the soxRS response is downregulated by overexpression of G6PDH from a multicopy plasmid (Giró et al., 2006), and induced by expression of NADPH-consuming enzymes and electron acceptors, including FPR, flavodoxin and desulfoferrodoxin (Gaudu et al., 2000; Krapp et al., 2002; Zheng et al., 1999). They also agree with observations made on $E$. coli $z w f$ mutants that are chronically NADPH-deficient and display an enhanced soxRS response (Liochev \& Fridovich, 1992). We therefore propose that the size and degree of reduction of the $\mathrm{NADP}(\mathrm{H})$ pool could influence the progress of the soxRS response and act as a signal of the cellular redox status for SoxR modulation. This signalling role could be exerted through the SoxR reductase activities, for which NADPH is the electron donor (Kobayashi \& Tagawa, 1999; Koo et al., 2003).

We used anaerobic conditions to show that the soxRS regulon can be activated in the absence of oxygen, but it is not clear if this activation confers any physiological advantage for cell welfare under anaerobiosis. By inducing G6PDH, it could help to maintain and/or increase NADPH levels when they are depleted by sudden metabolic demands or xenobiotics, but evidence for such a role is still lacking.
The nature of the physiological electron acceptor(s) of SoxR in the absence of oxidative stress remains elusive. The midpoint redox potential of purified E. coli SoxR is $-290 \mathrm{mV}$ (Ding et al., 1996), indicating that many cellular oxidants could react with SoxR and activate it in nonstressed cells. Since this is not the case, SoxR must be maintained in its reduced state by an active process, presumably mediated by the SoxR reductases. However, binding of SoxR to its target sequence in DNA results in an upward shift of the redox potential to $+200 \mathrm{mV}$ (Gorodetsky et al., 2008), therefore limiting activation to strong oxidants. It is at present unclear which of the two species, the soluble or the DNA-bound SoxR, is the actual sensor of the response. Oxygen could readily oxidize both SoxR forms, but this does not explain the activation of the regulon in anaerobiosis. Gorodetsky et al. (2008) have argued that oxidized pyocyanins could be the physiological electron acceptor in Pseudomonas, but the identity of the oxidant(s) in enterobacteria is unknown.

Surprisingly, alterations in NADPH levels, including those caused by oxidative stress, were accompanied by inversely correlated changes in total $\left(\mathrm{NADP}^{+}+\mathrm{NADPH}\right)$ contents (Fig. 1), so that they were not translated directly to $\mathrm{NADPH}: \mathrm{NADP}^{+}$ratios. A major increase in the total $\left(\mathrm{NADP}^{+}+\mathrm{NADPH}\right)$ pool has been reported for the transition from anaerobic to aerobic lifestyles in $E$. coli (Brumaghim et al., 2003), and in the closely related species Salmonella enterica (Grose et al., 2006). $\mathrm{NADP}^{+}$is synthesized from $\mathrm{NAD}^{+}$in a reaction catalysed by $\mathrm{NAD}^{+}$ kinase. This enzyme does not belong to the soxRS regulon (Blanchard et al., 2007), and its activity did not increase 
when $E$. coli cells were exposed to micromolar concentrations of $\mathrm{H}_{2} \mathrm{O}_{2}$ (Brumaghim et al., 2003). However, Grose et al. (2006) showed that $\mathrm{NAD}^{+}$kinase is reversibly inhibited in vivo by NADPH. Since Brumaghim et al. (2003) assayed the activity under standardized in vitro conditions (no NADPH present), this effect could have been overlooked. We therefore propose that NADPH consumption by Fd or MV could relieve $\mathrm{NAD}^{+}$kinase from feedback inhibition and favour de novo synthesis of $\operatorname{NADP}(\mathrm{H})$. Conversely, GAPN-expressing cells grown aerobically, with continuous production of NADPH, would keep the enzyme more inhibited than in wild-type bacteria, resulting in lower $\left(\mathrm{NADP}^{+}+\mathrm{NADPH}\right)$ accumulation. Further research will be required to substantiate this contention.

Besides downregulation of the soxRS response as demonstrated herein, elevated NADPH levels might also have additional pro-oxidant effects by acting as electron donors for the synthesis of hydroxyl radicals $\left(\mathrm{OH}^{\cdot}\right)$ via an $\mathrm{Fe}^{2+}$ dependent Fenton-type mechanism. Both NADPH and NADH can boost this reaction by reducing $\mathrm{Fe}^{3+}$ to $\mathrm{Fe}^{2+}$, either directly (Brumaghim et al., 2003) or as substrates for flavin reductase (Woodmansee \& Imlay, 2002). Then, reduced pyridine nucleotides could have either protective or damaging effects during oxidative stress episodes, and therefore their cellular concentrations must be tightly regulated to ensure the welfare of the stressed organism.

The effects of oxidants on pyridine nucleotide metabolism have shed some light on the nature of this regulation. On exposure of E. coli cells to sublethal $\mathrm{H}_{2} \mathrm{O}_{2}$ concentrations, two NADPH-producing enzymes were induced: G6PDH and respiration-dependent NADH-NADP ${ }^{+}$transhydrogenase, together with many scavenging and protective enzymes that oxidize NADPH (Brumaghim et al., 2003). In contrast, most $\mathrm{NAD}(\mathrm{H})$-dependent dehydrogenases and reductases failed to respond to the oxidative challenge (Brumaghim et al., 2003). An even sharper labour division among NADHand NADPH-linked enzymes occurs in the soil microbe Pseudomonas fluorescens, which does not deploy a soxRStype response. On exposure to the superoxide propagator menadione, several NADPH-dependent enzymes were induced, most conspicuously G6PDH and isocitrate dehydrogenase. In this prokaryote, $\mathrm{NAD}^{+}$-reducing dehydrogenases were downregulated (Singh et al., 2007).

Determinations of NADH and NADPH levels in aerobically grown enterobacteria have yielded conflicting results. Using $\left[{ }^{14} \mathrm{C}\right]$ nicotinamide labelling of $E$. coli cultures, Andersen \& von Meyenburg (1977) measured equivalent amounts of both reduced pyridine nucleotides. Similar results were obtained by Fuhrer \& Sauer (2009) and by Grose et al. (2006) in S. enterica, whereas Brumaghim et al. (2003) observed much higher levels of NADH. Such discrepancies could be due to the different growth media and conditions employed. However, a common feature in most reports is that when cells are exposed to oxidative challenges or adverse environments, the NADH pool tends to be depleted faster than the NADPH pool (see, for instance, Brumaghim et al., 2003). Preservation of NADPH is advantageous to the cell because the nucleotide can be used as hydride donor by the repair and scavenging enzymes recruited during the stress response. Woodmansee \& Imlay (2002) and Brumaghim et al. (2003) have argued that this shift also favours tolerance because NADPH is 16-fold less reactive than $\mathrm{NADH}$ in the reduction of transition metals and a worse substrate for flavin reductase, therefore reducing the amount of $\mathrm{OH}^{\cdot}$ radicals formed via Fenton chemistry.

We propose another advantage of the NADH-to-NADPH shift, at least in E. coli, which results from the possibility that by increasing NADPH levels it could self-regulate the soxRS response. G6PDH is rapidly induced at the onset of the soxRS response (Giró et al., 2006), leading to early accumulation of NADPH that could be used by scavenging and repair enzymes such as FPR, flavodoxin and OxyRdependent reductases and peroxidases, all NADPH consumers. As NADPH contents increase, however, higher activity of SoxR reductases will favour reduction and inactivation of the SoxR sensor, switching off the entire response. It is therefore likely that NADPH accumulation occurs early during soxRS induction and proceeds against the activities of FPR and other reductases until the regulon is self-restrained by negative feedback regulation. Through this modulation, facultative aerobes such as E. coli could control the dynamic interconversion of their pyridine nucleotides to obtain the maximal benefit from their chemical properties for defence and protection.

\section{ACKNOWLEDGEMENTS}

This research was supported by ANPCyT, Argentina (grant PICT0114648), and CONICET, Argentina (grant PID10777). N.C. and A. R. K. are staff members of CONICET. We wish to thank A. Iglesias (Instituto de Agrobiotecnología del Litoral, UNL, Argentina) for plasmid pRSETBGAPN, and F. Bologna and M. F. Drincovich (CEFOBI, UNR/CONICET, Argentina) for pGEMT-MaeB.

\section{REFERENCES}

Andersen, K. B. \& von Meyenburg, K. (1977). Charges of nicotinamide adenine nucleotides and adenylate energy charge as regulatory parameters of the metabolism in Escherichia coli. J Biol Chem 252, 4151-4156.

Apel, K. \& Hirt, H. (2004). Reactive oxygen species: metabolism, oxidative stress, and signal transduction. Annu Rev Plant Biol 55, 373399. doi:10.1146/annurev.arplant.55.031903.141701.

Blanchard, J. L., Wholey, W. Y., Conlon, E. M. \& Pomposiello, P. J. (2007). Rapid changes in gene expression dynamics in response to superoxide reveal soxRS-dependent and independent transcriptional networks. PLoS ONE 2, e1186. doi:10.1371/journal.pone.0001186.

Bologna, F. P., Andreo, C. S. \& Drincovich, M. F. (2007). Escherichia coli malic enzymes: two isoforms with substantial differences in kinetic properties, metabolic regulation, and structure. J Bacteriol 189, 5937-5946. doi:10.1128/JB.00428-07.

Brumaghim, J. L., Li, Y., Henle, E. \& Linn, S. (2003). Effects of hydrogen peroxide upon nicotinamide nucleotide metabolism in Escherichia coli: changes in enzyme levels and nicotinamide nucleotide 
pools and studies of the oxidation of $\mathrm{NAD}(\mathrm{P}) \mathrm{H}$ by $\mathrm{Fe}(\mathrm{III})$. J Biol Chem 278, 42495-42504. doi:10.1074/jbc.M306251200.

Bustos, D. M. \& Iglesias, A. A. (2002). Non-phosphorylating glyceraldehyde-3-phosphate dehydrogenase is post-translationally phosphorylated in heterotrophic cells of wheat (Triticum aestivum). FEBS Lett 530, 169-173. doi:10.1016/S0014-5793(02)03455-5.

Carrillo, N. \& Ceccarelli, E. A. (2003). Open questions in ferredoxin$\mathrm{NADP}^{+}$reductase catalytic mechanism. Eur J Biochem 270, 1900 1915. doi:10.1046/j.1432-1033.2003.03566.x.

Catalano Dupuy, D. L., Rial, D. V. \& Ceccarelli, E. A. (2004). Inhibition of pea ferredoxin-NADP $(\mathrm{H})$ reductase by $\mathrm{Zn}$-ferrocyanide. Eur J Biochem 271, 4582-4593. doi:10.1111/j.1432-1033.2004.04430.x.

Dietrich, L. E. P., Price-Whelan, A., Petersen, A., Whiteley, M. \& Newman, D. K. (2006). The phenazine pyocyanin is a terminal signalling factor in the quorum sensing network of Pseudomonas aeruginosa. Mol Microbiol 61, 1308-1321. doi:10.1111/j.1365-2958.2006.05306.x.

Ding, H., Hidalgo, E. \& Demple, B. (1996). The redox state of the [2Fe-2S] clusters in SoxR protein regulates its activity as a transcription factor. J Biol Chem 271, 33173-33175. doi:10.1074/jbc.271. 52.33173.

Fuhrer, T. \& Sauer, U. (2009). Different biochemical mechanisms ensure network-wide balancing of reducing equivalents in microbial metabolism. J Bacteriol 191, 2112-2121. doi:10.1128/JB.01523-08.

Gaudu, P. \& Fontecave, M. (1994). The NADPH : sulfite reductase of Escherichia coli is a paraquat reductase. Eur J Biochem 226, 459-463. doi:10.1111/j.1432-1033.1994.tb20070.x.

Gaudu, P., Dubrac, S. \& Touati, D. (2000). Activation of SoxR by overproduction of desulfoferrodoxin: multiple ways to induce the soxRS regulon. J Bacteriol 182, 1761-1763. doi:10.1128/JB.182.6.17611763.2000

Giró, M., Carrillo, N. \& Krapp, A. R. (2006). Glucose-6-phosphate dehydrogenase and ferredoxin-NADP $(\mathrm{H})$ reductase contribute to damage repair during the soxRS response of Escherichia coli. Microbiology 152, 1119-1128. doi:10.1099/mic.0.28612-0.

Gorodetsky, A. A., Dietrich, L. E., Lee, P. E., Demple, B., Newman, D. K. \& Barton, J. K. (2008). DNA binding shifts the redox potential of the transcription factor SoxR. Proc Natl Acad Sci U S A 105, 36843689. doi:10.1073/pnas.0800093105.

Grose, J. H., Joss, L., Velick, S. F. \& Roth, J. R. (2006). Evidence that feedback inhibition of NAD kinase controls responses to oxidative stress. Proc Natl Acad Sci U S A 103, 7601-7606. doi:10.1073/pnas. 0602494103.

Iddar, A., Valverde, F., Assobhei, O., Serrano, A. \& Soukri, A. (2005). Widespread occurrence of non-phosphorylating glyceraldehyde-3-phosphate dehydrogenase among Gram-positive bacteria. Int Microbiol 8, 251-258.

Imlay, J. A. (2008). Cellular defenses against superoxide and hydrogen peroxide. Annu Rev Biochem 77, 755-776. doi:10.1146/annurev.biochem.77.061606.161055.

Kobayashi, K. \& Tagawa, S. (1999). Isolation of reductase for SoxR that governs an oxidative response regulon from Escherichia coli. FEBS Lett 451, 227-230. doi:10.1016/S0014-5793(99)00565-7.

Koo, M. S., Lee, J. H., Rah, S. Y., Yeo, W. S., Lee, J. W., Lee, K. L., Koh, Y. S., Kang, S. O. \& Roe, J. H. (2003). A reducing system of the superoxide sensor SoxR in Escherichia coli. EMBO J 22, 2614-2622. doi:10.1093/emboj/cdg252.

Krapp, A. R., Rodriguez, R. E., Poli, H. O., Paladini, D. H., Palatnik, J. F. \& Carrillo, N. (2002). The flavoenzyme ferredoxin (flavodoxin)$\operatorname{NADP}(\mathrm{H})$ reductase modulates $\mathrm{NADP}(\mathrm{H})$ homeostasis during the soxRS response of Escherichia coli. J Bacteriol 184, 1474-1480. doi:10. 1128/JB.184.5.1474-1480.2002.
Liochev, S. I. \& Fridovich, I. (1992). Fumarase C, the stable fumarase of Escherichia coli, is controlled by the soxRS regulon. Proc Natl Acad Sci U S A 89, 5892-5896. doi:10.1073/pnas.89.13.5892.

Liochev, S. I., Hausladen, A., Beyer, W. F., Jr \& Fridovich, I. (1994). $\mathrm{NADPH}$ : ferredoxin oxidoreductase acts as a paraquat diaphorase and is a member of the soxRS regulon. Proc Natl Acad Sci U S A 91, 1328-1331. doi:10.1073/pnas.91.4.1328.

Manchado, M., Michán, C. \& Pueyo, C. (2000). Hydrogen peroxide activates the soxRS regulon in vivo. J Bacteriol 182, 6842-6844. doi:10. 1128/JB.182.23.6842-6844.2000.

Martínez, E., Bartolomé, B. \& de la Cruz, F. (1988). pACYC184derived cloning vectors containing the multiple cloning site and lac $Z \alpha$ reporter gene of pUC8/9 and pUC18/19 plasmids. Gene 68, 159-162. doi:10.1016/0378-1119(88)90608-7.

Miller, J. H. (1992). A Short Course in Bacterial Genetics: a Laboratory Manual for E. coli and Related Bacteria. Cold Spring Harbor, NY: Cold Spring Harbor Laboratory.

Nunoshiba, T., Hidalgo, E., Amábile Cuevas, C. F. \& Demple, B. (1992). Two-stage control of an oxidative stress regulon: the Escherichia coli SoxR protein triggers redox-inducible expression of the soxS regulatory gene. J Bacteriol 174, 6054-6060.

Nunoshiba, T., deRojas-Walker, T., Wishnok, J. S., Tannenbaum, S. R. \& Demple, B. (1993). Activation by nitric oxide of an oxidativestress response that defends Escherichia coli against activated macrophages. Proc Natl Acad Sci U S A 90, 9993-9997. doi:10.1073/ pnas.90.21.9993.

Paterson, E. S., Boucher, S. E. \& Lambert, I. B. (2002). Regulation of the $n f s A$ gene in Escherichia coli by SoxS. J Bacteriol 184, 51-58. doi:10.1128/JB.184.1.51-58.2002.

Pomposiello, P. J., Bennik, M. H. \& Demple, B. (2001). Genome-wide transcriptional profiling of the Escherichia coli responses to superoxide stress and sodium salicylate. J Bacteriol 183, 3890-3902. doi:10. 1128/JB.183.13.3890-3902.2001.

Privalle, C. T., Kong, S. E. \& Fridovich, I. (1993). Induction of manganese-containing superoxide dismutase in anaerobic Escherichia coli by diamide and 1,10-phenanthroline: sites of transcriptional regulation. Proc Natl Acad Sci U S A 90, 2310-2314. doi:10.1073/ pnas.90.6.2310.

Sedmak, J. J. \& Grossberg, S. E. (1977). A rapid, sensitive, and versatile assay for protein using Coomassie brilliant blue G250. Anal Biochem 79, 544-552. doi:10.1016/0003-2697(77)90428-6.

Singh, R., Mailloux, R. J., Puiseux-Dao, S. \& Appanna, V. D. (2007). Oxidative stress evokes a metabolic adaptation that favors increased NADPH synthesis and decreased NADH production in Pseudomonas fluorescens. J Bacteriol 189, 6665-6675. doi:10.1128/JB.00555-07.

Slater, T. F. \& Sawyer, B. (1962). A colorimetric method for estimating the pyridine nucleotide content of small amounts of animal tissue. Nature 193, 454-456. doi:10.1038/193454a0.

Watanabe, S., Kita, A., Kobayashi, K. \& Miki, K. (2008). Crystal structure of the $[2 \mathrm{Fe}-2 \mathrm{~S}]$ oxidative-stress sensor SoxR bound to DNA. Proc Natl Acad Sci U S A 105, 4121-4126. doi:10.1073/pnas. 0709188105.

Woodmansee, A. N. \& Imlay, J. A. (2002). Reduced flavins promote oxidative DNA damage in non-respiring Escherichia coli by delivering electrons to intracellular free iron. J Biol Chem 277, 34055-34066. doi:10.1074/jbc.M203977200.

Wu, J. \& Weiss, B. (1992). Two-stage induction of the soxRS (superoxide response) regulon of Escherichia coli. J Bacteriol 174, 3915-3920.

Zheng, M., Doan, B., Schneider, T. D. \& Storz, G. (1999). oxyR and soxRS regulation of fur. J Bacteriol 181, 4639-4643.

Edited by: M. S. Paget 